THE POSSIBILITY OF OPERATIONS ON THE ESOPHAGUS THROUGH THE STOMACH AS SHOWN BY DISSECTIONS. ${ }^{1}$

BY MAURICE H. RICHARDSON,

PROFESSOR OF ANATOMY IN HARVARD UNIVERSITY,

SURGEON TO THE MASSACHUSETTS GENKRAL HOSPITAI.

A LITTLE more than a year ago my attention was first drawn to this subject by the patient whom I shall have the honour to present here to-day. At the time he came to the Massachusetts General Hospital for relief, his condition was so deplorable, and immediate action was so imperative, that there was no time for any preliminary work upon the cadaver for the purpose of studying the best methods of performing what has proved to be a new operation in surgery. The details of this case have already been published, with some few observations on the operation and the anatomy of the cesophagus. ${ }^{2}$ Since that time I have made many dissections for the purpose of showing the best way of doing this operation, and of demonstrating the possibility of reaching any part of the cesophagus with the finger. In all the dissections the distance was measured from the upper incisors to the cardiac orifice, as well as that from the cardiac orifice to the point in the neck where external cesophagotomy is usually performed.

The patient, a man aged thirty-seven, tall and strong, weighing when in health from $160 \mathrm{lb}$. to $180 \mathrm{lb}$, had swallowed while eating a denture of four teeth. He had presented himself at the out-patient department of the bospital the next day, and I examined him then. The teeth were lodged near the cardiac end of the cesophagus. $\mathrm{He}$ was admitted to the hospital, and numerous attempts were made to dislodge them. At one time sufficient traction was used to break the coin probang which had been made fast to the plate. He was finally discharged from the hospital, having gained in weight, and it was thought that the foreign body had passed into the stomach.

Eleven months after the accident the man came again to the hospital, and the foreign body was found to be in the same place as before, fourteen inches from the upper incisors. The patient was reduced to $113 \mathrm{lb}$. in weight. He had continual pain, and it was with great difficulty that he was able to swallow enourgh liquid food to keep him alive. There were two methods of procedure possible, all attempts at removal through the mouth having failed: one by external cesophagotomy, in the manner described by Dr. Leroy Maclean of Troy, and so successfully performed by him; ${ }^{3}$ and the otber through the abdominal wall asd stomach. I selected the latter method because it had heen shown that the plate was very firmly impacted indeed, and it was very probable that it would be necessary to use the fingers in dislodging it. For two days before the operation the patient was nourished by enemata, and nothing was taken into the stomach but water and stimulants. After etherisation a cut was made parallel to the lower margin of the ribs on the left side, six inches in length, through which the stomach was drawn and held upon aseptic towels by assistants. A small opening through the stomach wall was next made midway between the curvatures, and forceps introduced for the purpose of grasping the plate. The cardiac opening could not be found. The cut was then enlarged enough to admit the right hand, which was introduced till the cesophageal opening was found. The foreign body was detected by the fingers about two inches above the diaphragm ; after considerable careful manipulation with the index and middle fingers the plate was detached and removed. The mucous membrane of the stomach was closed with a continuous silk suture, after the method of Lembert. The patient made a good recovery, though complicated by slight lung symptoms, caused probably by the breaking of a small peri-œsophageal abscess into the lung by the manipulation of the fingers. He rapidly gained in weight from $113 \mathrm{lb}$. to $167 \mathrm{lb}$, and went to work as a teamster. He is now perfectly well, and able to do as hard a day's work as any man. In the selection of the above operation and in its first performance various questions

1 Read in the Surgical Section of the International Medical Congress beld at Washington.

Bosten Medical and Surgical Journal, Dec. 16th. 1886.

3 New York Medical Record, vol. xxvi., p. 282. arose, to the solution of which I devoted what little time I had. As will be seen, I was ignorant of several important points which $I$ have since demonstrated. I am positive that the foreign body could have been removed with instruments had I known at the time what now I do about the subject.

During the past winter I have operated on sixty patients, and made various observations, the general result of which I herewith submit. The first question that naturally arose was as to the exact location of the foreign body with reference to the cardiac end of the cesophagus, and also with reference to the cricoid cartilage, in order that an intelligent choice might be made between gastrotomy and external osophagotomy, it being taken for granted that that operation is better in which it is possible to use the fingers if instruments fail. The second question was:What portion of the cesoplagus is accessible to the fingers after the operation of external csophagotomy, and what after gastrotomy? If gastrotomy is first performed, the best incision through the abdominal wall for reaching the cardiac end with the finger, and the best where instruments are to be introduced? Finally, the best incision through the walls of the stomach, and the details of the operation as to the manipulation of the stomach and oesophagus.

Location of the foreign body (or condition requiring operation).- If it is known how tar the obstruction is from the upper incisors when the head is thrown back, in the position for passing the exploring probang, and if the distance from the same point to the cardiac opening is determined, it is evident that we can tell immediately whether the obstruction can be reached from below or not. The results obtained in the measurement of fifty-five subjects show that the distance from the upper incisors to the opening in the diaphragm is not constant. The average distance is fourteen inches and a half $(368 \mathrm{~cm}$.). Unfortunately there is no constant ratio between the height of the individual and this measurement. One subject six feet in height measured between the points mentioned fourteen inches and a quarter. Another, with a height of four feet ten inches, measured fifteen inches and a half. The greatest distance was seventeen inches, and the least ten and a quarter. The average distance from the cricoid cartilage to the cardiac opening was seven inches and a half in nineteen subjects, taken at random. The greatest distance was nine inches and a quarter, and the least six and a half. From these figures it must be said that it is not possible to locate the foreign body accurately, with reference either to the cardiac opening or the cricoid cartilage. If the individual is of average height, and with a neck of ordinary length, it is safe to say that the distance from the incisors to the diaphragm is about fourteen inches and a balf. If the probang is arrested at a point more than thirteen inches from the incisors, the point of obstruction is probably at or near the cardiac end of the cosophagus. Inasmuch as the cesophagus is constricted at the diaphragm, it goes without saying that foreign bodies that have passed the constriction at the upper end are probably at the cardiac end. All parts of the oesophagus are accessible to the finger, either by gastrotomy or by external cesophagotomy.

In all the subjects examined, this fact was observed: In some of them it was quite difficuli to reach every part, but it was nevertheless possible. The method of rnaking these observations was to do first an external œesophagotomy in the usual way. Then the stomach was opened and the fingers of the left hand introduced into the cardiac opening. With the forefinger of the right hand in the upper wound and the forefinger and middle finger of the left hand in the lower end of the osophagus, it was found possible, not only to make the fingers touch, but in many cases to make them overlap quite a distance. Coins and other bodies were passed from one hand to the other in both directions with great ease. In some cases it was necessary to use both the index and middle fingers of the right hand as well as the left.

It cannot be denied that these conditions of observation cannot be reproduced on the living subject, and that the results are therefore only approximate. It would be hardly practicable to do both operations on the same patient. If both hands are in use pushing towards each other it is of course much easier to bring the fingers together and to push the foreign body from one finger to the other waiting to receive it. Yet even in the living I think it is safe to say that there is no point in the cesophagus which cannot be reached by the finger, etther from above or below. The other source of error is in the fact that in the cadaver the 
diaphragm is relaxed. This does not make any appreciable difference, however, because the opening in the diaphragm is so fixed to the bodies of the vertebræ that it does not share to any extent in the contractions of that muscle. It is possible to reach with the left hand three inches above the cardiac opening - that is to say, the length of the left middle finger. From above, through the wound in the neck, one cannot reach quite so far on account of the sternum and clavicle. One can, however, easily reach the arch of the aorta, and even hook the finger under it in some cases. In a few of the dissections, the measurement was made between the centre of the incision in the neck to the diaphragm. The distance was a little over six inches. Allowing in the average neck an inch and a half to two inches from the cricoid cartilage to the lower point of the incision in the oesophagus, in external œsophagotomy we have the average distance from that incision to the cardiac opening of five and a half to six inches.

The general conclusion to which I have arrived from these measurements and digital explorations is that the obstruction can be reached by the finger in all or nearly all cases when it is situated more than six inches below the cricoid cartilage. If less than six inches below the cricoid ring, it can be reached best from above, though in some few cases it may be just beyond the reach of the finger. Even in these cases instruments can be easily and intelligently applied. The measurements of the point of inspection or obstruction having been carefully made, and it having been demonstrated that the point in the oesophagus to be reached if necessary by the finger is not less than thirteen inches from the upper incisors or six from the cricoid cartilage, the operation of gastrotomy should be performed.

Inasmuch as the best argument in favour of gastrotomy is that the fingers may be used to detach the foreign body if all other means fail, it is evident that the probability of the introduction of the hand into the stomach is the most important element in the selection of the incision through the abdominal wall. In the case of the patient upon whom I have done this operation it seemed to me best to make an oblique incision under the margin of the ribs on the left side, directly over the stomach. By this incision the stomach can be recognised very easily, and drawn out of the wound so far that the subsequent manipulations can be made without the escape of the contents into the peritoneal cavity. From a large number of dissections for the purpose of deciding the question of incision in the abdominal wall, I have come to the conclusion that the oblique cut is the best on the whole for this operation, although the fingers can be introduced into the oesophagus with ease after making the median cut. The incision through the walls of the stomach for the purpose of introducing instruments into the cardiac end of the cesophagus may be made anywhere, provided that it is far enough to the right to avoid the convexity of the lesser curvature. All that is necessary is to put the lesser curvature on the stretch, so that it makes a straight line to the diaphragmatic opening. The cut through the stomach wall must be far enough to the right to allow the passage of the instrument along the sulcus between the anterior and posterior walls of the stomach, made tense as above. If the instrument is brought obliquely to this groove and passed upwards, all the time being pressed gently against the straightened lesser curvature, it will glide into the ossophagus every time with the greatest ease.

The incision in the median line was made on many subjects, and the conclusion was that it is the better method of operation where it is intended only to pass instruments into the cesophagus. In these observations it was found practicable to pass instruments into the cesophagus and withdraw coins with the greatest ease through an abdominal cut in the median line only two inches and a half in length. By enlarging the incision it was found to be quite practicable to introduce the hand into the stomach and pass the fingers into the osophagus, but not so easy as by the oblique incision. It was also much more difflcult to draw the stomach out of the peritoneal cavity enough to avoid the escape of the contents of the stomach into the abdominal cavity. The stomach having been exposed by the lateral cut through the abdominal walls, and having been drawn out of the wound, it must be held by an assistant in such a way that the lesser curvature is put on the stretch. It is better for the assistant to hold the stomach in both hands, so that the whole viscus is flattened nut. He should stand on the left of the patient, and grasp the greater cur- vature. The operator standing on the right of the patient, holds the lesser curvature between the lett thumb and forefinger, thereby making tense the lesser curvature and assisting in the parsage of the instrument. Betore doing this, it is best to introduce the hand into the peritoneal cavity and examine the diaphragmatic opening externally. With the stomach held as described, the opening through its walls may be made anywhere in the flattened surface, so as to avoid the large vessels. It goes without saying that the incisions should first lie just large enough to get hold of the stomach with the thumb and fingers and draw it out so as to stretch the lesser curvature. An incision through the stomach wall can then be made large enough to introduce the instrument, by which, I believe, the foreign body can be removed with ease in the majority of cases. In cases of stricture of the osophagus, the instrument can be passed with very small openings both in the abdominal walls and in the stomach itself. The wounds in the stomach and abdominal wall should be closed in the usual manner.

In the selection of the operation, whether by external osophagotomy or by gastrotomy, another reason for the choice of the latter operation is that there is less danger of wounding important structures in the thorax, where the traction is downwards. than upwards. If the body is at the orifice, it is not in direct relation with either pleura, heart, or aorta. There is much less danger of lacerating the osophageal wall in pulling down the foreign body a short distance than in pulling it up a considerable one. Finally, the prognosis after laparotomy and gastrotomy where the opening in the stomach is small I believe to be very good indeed. As to the frequency of the conditions requiring this operation, with the exception of impacted foreign bodies and stricture of the cesophagus, I know of no indication for the operation. It is certainly within the experience of nearly every surgeon that foreign bodies do become impacted low down in the osophagus, and that the dangers which arise therefrom are very great. It is in the bope that in such cases this method which I have described will be tried that I submit these observations. Since Labbés successful case in 1875 to the present time there has been no reported fatal case of laparotomy and gastrotomy for foreign body in the stomach. In the two fatal cases, one had been preceded by an external oesophagotomy, and in the other the stomach wall had been perforated by the foreign body. The list comprises the cases of Labbe, Cocher, Ediouborn, Thornton, Billroth, Credé, Bernay, and Polaillon.

\section{AN EXPERIMENTAL CONTRIBUTION TO INTESTINAL SURGERY. ${ }^{1}$}

WITH SPECIAL REFERENCE TO THE TREATMENT OF INTESTINAL OBSTRUCTION.

By N. SENN, M.D , PH.D., Milwaukfe, Wis., ATTENDING 8URGEON TO THE MILWAUKEE HOSPITAL; PROFESSOR OF THE PRLNCIPLES AND PRACTICE OF SURGERY AND CLINICAL SURGERY IN THE COLIEGE OF PHYSICIANS AND SURGEONS, CHICAGO, ILL.

\section{THE following is a synopsis of the paper:-}

\section{Artifictal Intestinal Obstruction.}

1. Stenosis.-(a) Partial enterectomy and longitudinal suturing of wound. Traumatic stenosis from this cause becomes a source of danger from obstruction or perforation in all cases where the lumen of the bowel is reduced more than one-half in size. Longitudinal suturing of wounds on the mesenteric side of the intestine should never be practised, as such a procedure is invariably followed by gangrene and perforation by intercepting the vascular supply to the portion of bowel which corresponds to the mesenteric defect. (b) Circular constriction of intestine. The immediate cause of gangrene in circular constriction of a loop of intestine is due to obstruction of the venous circulation, and takes place first at a point most remote from the cause of the obstruction.

2. Flexion.-(a) Flexion produced by partial enterectomy and transverse suturing of wound. On the convex surface

Read in the Surgical Section of the International Medical Congress held at Washington. 